\title{
Molecular epidemiology of Streptococcus pneumoniae isolated from pediatric community-acquired pneumonia in pre-conjugate vaccine era in Western China
}

\author{
Zhuoxin Liang ${ }^{1 \dagger}$, Jinjian $\mathrm{Fu}^{1 \dagger}$, Ling $\mathrm{Li}^{2+}$, Rongsong $\mathrm{Yi}^{1}$, Shaolin $\mathrm{Xu}^{1}$, Jichang Chen ${ }^{1}$, Xiaohua Ye ${ }^{3^{*}}$ and
} Eric McGrath ${ }^{4,5}$

\begin{abstract}
Background: Streptococcus pneumoniae (S. pneumoniae) is one of the most common pathogens which can cause morbidity and mortality in pediatric infections worldwide. This study aimed to describe the phenotypic and molecular characteristics of community-acquired pneumonia (CAP)-causing S. pneumoniae recovered from children in Western China.

Methods: We retrospectively enrolled pediatric patients younger than 5 years diagnosed with CAP. All 419 S. pneumoniae isolates were tested for antibiotic susceptibility, serotypes, virulence genes, resistance genes, and sequence types. The potential relationships between molecular characteristics were tested by correspondence analysis.

Results: Most of S. pneumoniae isolates were resistant to erythromycin, tetracycline, clindamycin and trimethoprimsulfamethoxazole, with 93.8\% isolates classified as multidrug resistant. The dominant STs were ST271 (30.8\%) and ST320 (12.2\%), while the prevailing serotypes were $19 \mathrm{~F}(46.8 \%), 6 \mathrm{~B}(11.5 \%), 23 \mathrm{~F}(9.5 \%)$ and $19 \mathrm{~A}(9.3 \%)$. The coverage rates of PCV-7 and PCV-13 were $73.03 \%$ and $86.16 \%$, while the coverage rates of PCV13 among children aged $<1$ year and $1-2$ years were high in $93.18 \%$ and $93.62 \%$. We also observed that CC271 expressed more of mef (A/E), IytA, rlrA and sipA than non-CC271 isolates. Moreover, there were strong corresponding relationships between molecular characteristics.
\end{abstract}

Conclusions: The high coverage rate of PCV13 suggests the necessity of introducing the PCV13 vaccine in Western China. Our findings underscore the value of monitoring multiple molecular characteristics to provide new guidance for developing future pneumococcal vaccines.

Keywords: Community-acquired pneumonia, Streptococcus pneumoniae, Children, Vaccine, Molecular characteristics

*Correspondence: smalltomato@163.com

†Zhuoxin Liang, Jinjian Fu and Ling Li contributed equally

${ }^{3}$ Laboratory of Molecular Epidemiology, School of Public Health,

Guangdong Pharmaceutical University, 283\# Jianghai Dadao, Haizhu District, 510310 Guangzhou, China

Full list of author information is available at the end of the article

\begin{abstract}
Introduction
Community-acquired pneumonia (CAP) is a common childhood disease around the world. The overall percentage of CAP and the causative pathogens varied geographically, especially in developing countries. According to the World Health Organization (WHO), there are more than 900,000 deaths per year in children under than 5 years who have suffered from CAP [1]. Streptococcus pneumoniae (S. pneumoniae) is one of the most common
\end{abstract}

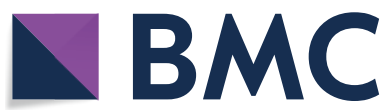

(c) The Author(s) 2021. This article is licensed under a Creative Commons Attribution 4.0 International License, which permits use, sharing, adaptation, distribution and reproduction in any medium or format, as long as you give appropriate credit to the original author(s) and the source, provide a link to the Creative Commons licence, and indicate if changes were made. The images or other third party material in this article are included in the article's Creative Commons licence, unless indicated otherwise in a credit line to the material. If material is not included in the article's Creative Commons licence and your intended use is not permitted by statutory regulation or exceeds the permitted use, you will need to obtain permission directly from the copyright holder. To view a copy of this licence, visit http://creativeco mmons.org/licenses/by/4.0/. The Creative Commons Public Domain Dedication waiver (http://creativecommons.org/publicdomain/ zero/1.0/) applies to the data made available in this article, unless otherwise stated in a credit line to the data. 
causes of bacterial CAP in children and was of great concern in pediatric CAP, accounting for $2.2-50.9 \%$ of cases younger than 5 years [2].

Pneumococcal conjugate vaccines (PCVs) targeting 7, 10, or 13 of more than 90 serotypes of S. pneumoniae have been successively introduced to reduce the pediatric pneumococcal disease burden around the world [3]. PCV7 vaccination was associated with a $19 \%$ and $33.1 \%$ reduction in the rate of CAP in children aged $<5$ years and aged $<2$ years, respectively, in the UK. But for unvaccinated children, there was no significant reduction in the incidence of CAP [4]. After introduction of PCV13 into the national immunization program in the USA, there was a $21 \%$ reduction in hospital admissions for allcause CAP in children aged $<2$ years, suggesting a positive impact of PCV immunization on CAP in children [5], especially for those caused by unique PCV13 serotypes of pneumococcal isolates which was not covered within PCV7, which were further decreased across each age group [3].

The highest prevalence of CAP was recorded in Chinese children aged $<6$ months around the developing countries (37.88\%) [6] and S. pneumoniae was responsible for $5.2 \%$ of CAP in children aged $<5$ years [7]. Although PCVs can reduce the burden of pneumococcal diseases, the PCV7 was not included as part of the national immunization schedule due to its high price in China. The coverage of PCV7, -10 , and -13 was $62.6 \%, 64.8 \%$ and $79.6 \%$, respectively before the licensing of PCV7 [8]. The coverage of PCV7, -10 , and -13 was changed into $58.6 \%, 59.4 \%$ and $85.1 \%$, respectively in Shanghai [9]. The PCV7 was imported into and licensed in China in 2008, but immunization rates were less than $10 \%$ in published studies. The PCV7 vaccine was removed from the market in 2015 and PCV13 was available in some big cities, but in Western China, such as Liuzhou, this vaccine has not been introduced yet.

Despite a well-developed knowledge of serotypes and antibiotic susceptibility of $S$. pneumoniae reported in China, little has been known on the potential relationship between STs, serotypes and molecular characteristics such as pilus genes. Therefore, we conducted this study of $S$. pneumoniae causing CAP in children aged $<5$ years to characterize the antimicrobial susceptibility, serotypes, ST profiles, virulence genes and pilus gene of S. pneumoniae isolates, so as to provide implication for the formulation of multivalent pneumococcal vaccines.

\section{Materials and methods}

\section{Study area and population}

This retrospective study was conducted from January 2015 and January 2017 in two tertiary hospitals of Liuzhou. Almost $80 \%$ of the children infections have been treated in these two hospitals in Liuzhou city. A suspicion of CAP was based on at least one of the following symptoms: new onset of systemic infection such as chills, pain, sweat, or temperature $>38^{\circ} \mathrm{C}$, and at least one of the acute lower respiratory tract infection symptoms (such as cough, chest pain, dyspnea, respiratory secretions, and abnormal auscultation). The suspicion CAP was confirmed for the chest radiograph or a computerized tomographic scan of the chest [10]. The eligibility criteria for enrollment into the study were as follows: (1) diagnosed as CAP (based on above criteria); (2) aged less than 60 months; (3) sputum, blood or alveolar lavage fluid specimens cultured and isolated S. pneumoniae; and (4) all children not vaccinating against $S$. pneumoniae.

$S$. pneumoniae isolates were classified as multidrugresistant (MDR) if they were resistant to 3 or more classes of antibiotics. PCVs coverage were defined as coverage of identified serotypes of all the isolates in this study.

\section{Specimen culture, identification and antimicrobial susceptibility testing}

Specimens were collected by the physicians or nurses and delivered to the clinical microbiology laboratory within 30 minutes. The specimens were cultured onto Columbia Agar with $5 \%$ sheep blood plates and placed in $35^{\circ} \mathrm{C}$, $5 \% \mathrm{CO}_{2}$ incubated for $24 \mathrm{~h}$ to $48 \mathrm{~h}$. Blood cultures were incubated using the BacT/Alert 3D system (bioMerieux). The positive pathogens were selected and incubated onto Columbia Agar with 5\% sheep blood plates. S. pneumoniae was identified by the VITEK 2 compact automatic microbial analysis system (Biomérieux, Marcyl' Etoile, France). The antimicrobial susceptibility testing was conducted according to the previous study (penicillin, vancomycin, erythromycin, levofloxacin, tetracycline, trimethoprim-sulfamethoxazole, chloramphenicol, and cefotaximea) [11]. E-test method was added to test clindamycin and linezolid according to the previous study [12].

\section{Serotyping}

Multiplex polymerase chain reaction (m-PCR) methods was used to identified all pneumococcal isolate serotypes. The primers and reaction conditions were used as described in previous studies [13, 14]. CpsA gene found in all known pneumococcal serotypes was used as the positive control.

\section{Antimicrobial resistance genes and virulence genes detecting}

The macrolide-resistant genes $(\operatorname{erm}(\mathrm{A}), \operatorname{erm}(\mathrm{B})$ and $m e f(\mathrm{~A} / \mathrm{E}))$, tetracycline resistance genes $(\operatorname{tet}(\mathrm{K})$, tet $(\mathrm{L})$ and tet $(\mathrm{O})$ ) were amplified by PCR methods, and the primers and PCR conditions were used as previously described 
$[15,16]$. Virulence genes (ply, pasA, lytA, and pspA) and pilus genes ( $r l r A$ for PI-1 and $\operatorname{sip} A$ for PI-2) were detected as previous studies described [15].

\section{Multilocus sequence typing}

Multilocus sequence typing (MLST) of the seven housekeeping genes (aroE, gdh, gki, recP, spi, $x p t$, and $d d l$ ) was conducted using primers and protocols as previously described [17]. Allelic profiles and STs were assigned by querying the pneumococcal MLST database (https:// pubmlst.org/spneumoniae).

\section{Statistical analysis}

Categorical variables were compared using Pearson's chi-squared $\left(x^{2}\right)$ test or Fisher exact test. Correspondence analysis was used to determine the internal relations between the serotypes and STs, and between STs and pilus genes. A two-sided $P$-value $<0.05$ was considered as being of statistical significance. All statistical analyses were conducted using Stata version 14.0 (Stata Corp LP, College Station, Texas, USA).

\section{Ethics statement}

The study was approved by the Ethics Committee of Liuzhou Maternity and Child Healthcare Hospital, and it was performed in accordance with the approved guidelines as described previously [12]. The informed consents were signed by guardian before the enrollment.

\section{Results}

\section{Demographic and clinical characteristics of study participants}

A total of 419 children with S. pneumoniae CAP were included. A total of 259 boys (61.8\%) and 160 (38.2\%) girls were suffered from S. pnuemoniae CAP. The ages of study participants ranged from 0 to 5 years, with average age $1.39 \pm 1.19$ years. The frequency distribution of age groups was $184(43.9 \%)$ aged $<1$ year, $132(31.5 \%)$ aged $1-2$ years, and $103(24.6 \%)$ aged $>2$ years.

\section{STs, serotypes and PCVs coverage}

There were 79 sequence types (STs) detected in this study. The dominant STs were ST271 (30.8\%) and ST320 (12.2\%). The most important clonal complex (CC) was CC271 (182 isolates, 43.4\%). There were 15 serotypes detected in this study, and the prevailing serotypes were 19F (46.8\%), 6B (11.5\%), 23F (9.5\%), and 19A (9.3\%). The coverage rates of PCV-7, PCV-10 and PCV-13 were $73.03 \%, 73.51 \%$ and $86.16 \%$, respectively (Fig. 1). The coverage rates of PCV7 among CAP children aged $<1$ year, $1-2$ years and $>2$ years were $78.03 \%, 73.05 \%$ and $69.90 \%$, respectively, while the coverage rates of PCV13 among 3 groups were $93.18 \%$, $93.62 \%$ and $77.67 \%$, respectively (Fig. 1 ).

\section{Antimicrobial resistance and virulence genes}

There were $94.3 \%, 87.8 \%, 94.7 \%$ and $81.1 \%$ isolates resistant to erythromycin, tetracycline, clindamycin and trimethoprim-sulfamethoxazole, respectively (Table 1). The resistance rate of tetracycline, trimethoprim-sulfamethoxazole, clindamycin and cefotaxime in the $\mathrm{CC} 271$ group was significantly higher than that in the non-CC271 group $(P<0.05$, Table 1$)$.

There was $93.8 \%$ S. pneumoniae classified as MDR, and the most common MDR profile was erythromycin-tetracycline-clindamycin-trimethoprim-sulfamethoxazole and erythromycin-tetracycline-clindamycin-trimethoprim-sulfamethoxazole-cefotaxime (Table 2). Penicillin retained high levels of susceptibility in tested isolates. Among all MDR isolates, the coverage rates of PCV7, PCV10, and PCV13 were $73.8 \%, 74.3 \%$ and $87.3 \%$, respectively.

There were $91.9 \%, 57.0 \%$ and $95.9 \%$ isolates carrying $\operatorname{erm}(\mathrm{B}), \operatorname{ermf}(\mathrm{A} / \mathrm{E})$ and $\operatorname{tet}(\mathrm{M})$ genes, respectively (Table 3). There were more CC271 isolates carried $m e f(\mathrm{~A} / \mathrm{E})$ than non-CC271 isolates $(P<0.001)$, while there were more non-CC271 isolates carried tet $(\mathrm{L})$ gene than CC271 isolates $(P=0.021)$. There were $403(96.2 \%)$ isolates carried lyt $A$ gene, the carriage rate of $l y t A$ gene in the CC271 group was higher than that in the non-CC271 group $(P<0.001)$. The carriage rate of $r l r A$ in the CC271 group was higher than that in the non-CC271 group $(P<0.001)$, and similar differences between $\mathrm{CC} 271$ and non-CC271 isolates were found for the sipA gene.

\section{Relationship between STs, serotypes, and pilus genes}

The correspondence analysis indicated that there was a significant corresponding relationship between serotypes and STs $\left(\chi^{2}=255.59, P<0.001\right.$; Fig. 2$)$. For example, serotype 19A was associated with ST320, serotype 23F was associated with ST81, serotype 6B was associated with ST90/ST902/ST3173/ST9789, serotype 15B/C was associated with ST3397, and serotype 19F was associated with ST271 and ST320. Additionally, we also revealed a significant corresponding relationship between STs and PIs (such as ST90/ST872/ST3397 and PI-1, ST320/271 and PI-1+PI-2, and ST320/271 and PI-2; $X^{2}=127.27$, $P<0.001$; Fig. 2).

\section{Discussion}

This study demonstrated that most of the S. pneumoniae isolated from CAP were resistant to erythromycin, tetracycline, clindamycin, and trimethoprim-sulfamethoxazole, and the MDR rate was as high as $93.8 \%$. The prevalent STs were ST271 and ST320, whereas the 


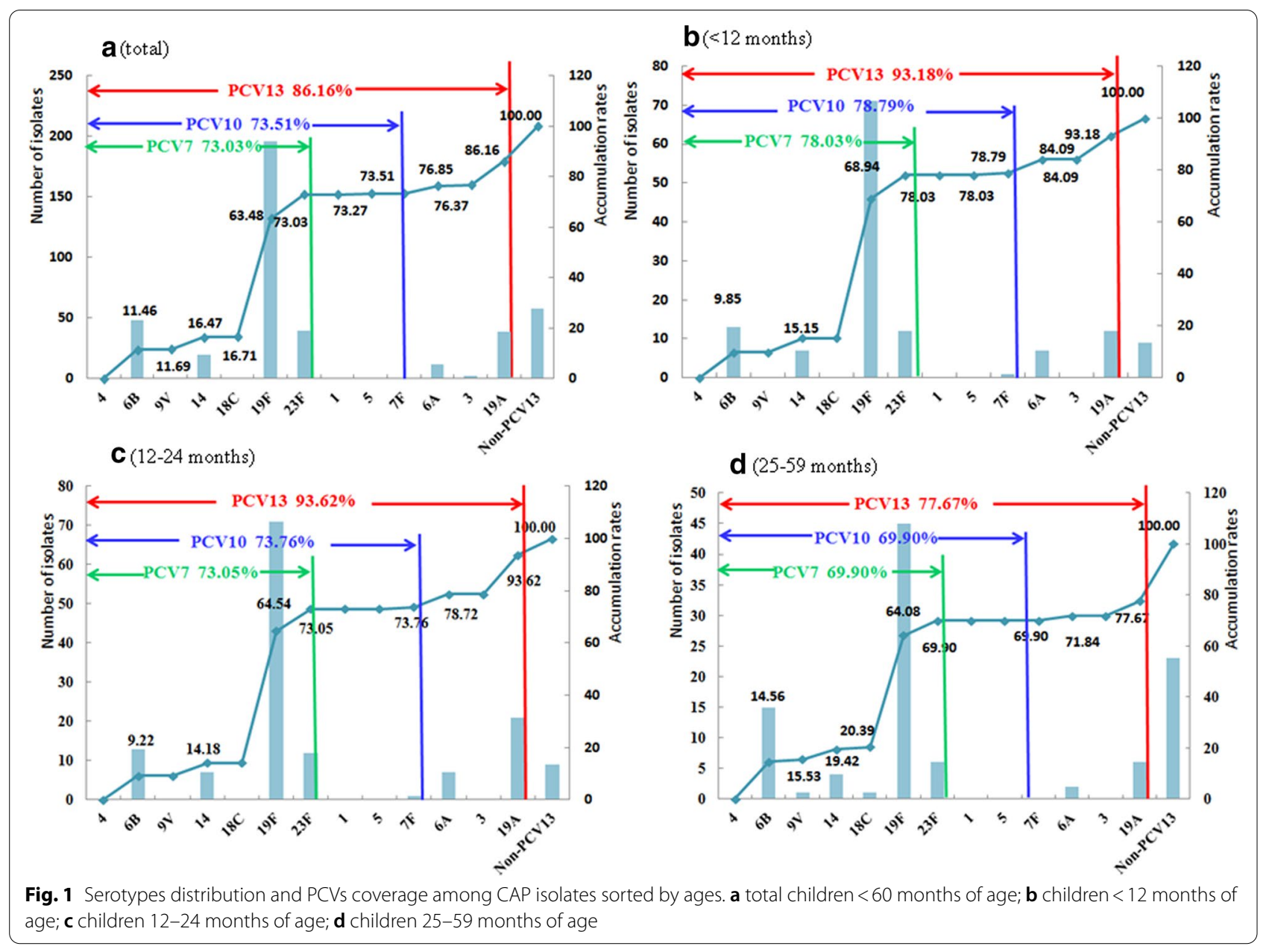

Table 1 Antimicrobial susceptibility of S. pneumoniae isolated from children with CAP

\begin{tabular}{|c|c|c|c|c|c|c|c|c|}
\hline \multirow[t]{2}{*}{ Antibiotic } & \multicolumn{2}{|c|}{ CC271 $n(\%)(n=182)$} & \multicolumn{2}{|c|}{ Non-CC271 $n(\%)(n=237)$} & \multicolumn{2}{|c|}{ Total $n(\%)(n=419)$} & \multirow[t]{2}{*}{$x^{2}$} & \multirow[t]{2}{*}{$P$} \\
\hline & $\mathbf{R}$ & $S$ & $\mathbf{R}$ & $S$ & $\mathbf{R}$ & $S$ & & \\
\hline Penicillin Parenteral ${ }^{a}$ & $5(2.7)$ & $177(97.3)$ & $1(0.4)$ & $236(99.6)$ & $6(1.5)$ & $413(98.5)$ & 2.47 & 0.116 \\
\hline Vancomycin & $0(0.0)$ & $182(100.0)$ & $0(0.0)$ & $237(100.0)$ & $0(0.0)$ & $419(100.0)$ & - & - \\
\hline Erythromycin & $175(96.2)$ & $7(3.8)$ & $220(92.8)$ & $17(7.2)$ & $395(94.3)$ & $24(5.7)$ & 2.11 & 0.146 \\
\hline Levofloxacin & $2(1.1)$ & $180(98.9)$ & $2(0.8)$ & $235(99.2)$ & $415(99.0)$ & $4(1.0)$ & 0.00 & 1.000 \\
\hline Tetracycline & $169(92.9)$ & $13(7.1)$ & $200(84.4)$ & $37(15.6)$ & $368(87.8)$ & $51(12.2)$ & 7.03 & 0.008 \\
\hline Trimethoprim-sulfamethoxazole & $167(91.8)$ & $15(8.2)$ & $202(85.2)$ & $35(14.8)$ & $369(88.1)$ & $50(11.9)$ & 4.17 & 0.041 \\
\hline Linezolid & $15(8.2)$ & $167(91.8)$ & $20(8.4)$ & $217(91.6)$ & $35(8.4)$ & 384 (91.6) & 0.01 & 0.942 \\
\hline Clindamycin & 177 (97.3) & $5(2.7)$ & $220(92.8)$ & $17(7.2)$ & 397 (94.7) & $22(5.3)$ & 4.05 & 0.044 \\
\hline Chloramphenicol & $7(3.8)$ & $175(96.2)$ & $14(5.9)$ & $223(94.1)$ & $21(5.0)$ & $398(95.0)$ & 0.92 & 0.338 \\
\hline Cefotaxime $^{\mathrm{a}}$ & $81(44.5)$ & $101(55.5)$ & $39(16.5)$ & 198 (83.5) & $120(28.6)$ & $299(71.4)$ & 39.63 & $<0.001$ \\
\hline
\end{tabular}

Italic values indicate significance of $P$ value $(P<0.05)$

CAP: community-acquired pneumonia

a 2016 CLSI breakpoints were considered for non-meningitis 
Table 2 Multidrug resistance patterns of S. pneumoniae isolated from children with CAP

\begin{tabular}{|c|c|c|}
\hline Resistance patterns & No.(\%) & Related serotypes (No.) \\
\hline P-E-TE-DA-SXT-CTX & $4(0.9)$ & $19 F(3), 23 F(1)$ \\
\hline P-E-LEV-TE-DA-SXT-CTX & $1(0.2)$ & $19 F(1)$ \\
\hline P-E-DA-SXT & $1(0.2)$ & $19 F(1)$ \\
\hline E-TE-DA-SXT-LZD-CL & $1(0.2)$ & $6 \mathrm{~B}(1)$ \\
\hline E-TE-DA-SXT-LZD & $17(4.1)$ & $6 \mathrm{~B}(1), 19 \mathrm{~A}(4), 19 \mathrm{~F}(10), 23 \mathrm{~F}(2)$ \\
\hline E-DA-SXT-LZD & $10(2.4)$ & $6 \mathrm{~B}(2), 15 \mathrm{~B} / \mathrm{C}(2), 15 \mathrm{~A}(1), 19 \mathrm{~A}(1), 19 \mathrm{~F}(2), 23 \mathrm{~F}(2)$ \\
\hline E-DA-SXT & $2(0.4)$ & $19 F(2)$ \\
\hline E-SXT-LZD & $1(0.2)$ & $19 F(1)$ \\
\hline E-LEV-TE-DA-SXT-CTX & $2(0.4)$ & $3(1), 19 F(1)$ \\
\hline E-LEV-TE-DA & $1(0.2)$ & UT (1) \\
\hline E-TE-DA-SXT-CL-CTX & $7(1.7)$ & $6 \mathrm{~A}(1), 19 \mathrm{~F}(6)$ \\
\hline E-TE-DA-SXT-CL & $11(2.6)$ & $6 \mathrm{~A}(2), 6 \mathrm{~B}(5), 14(1), 19 \mathrm{~F}(1), 23 \mathrm{~F}(1), 35 \mathrm{~B}(1)$ \\
\hline E-TE-DA-CL & $1(0.2)$ & $7 F(1)$ \\
\hline E-TE-SXT-CTX & $2(0.4)$ & $19 F(2)$ \\
\hline E-TE-DA-CTX & $1(0.2)$ & $19 F(1)$ \\
\hline TE-DA-CTX & $1(0.2)$ & $19 \mathrm{~A}(1)$ \\
\hline E-TE-DA-SXT-CTX & $101(24.1)$ & $6 \mathrm{~A}(2), 6 \mathrm{~B}(2), 14(1), 15 \mathrm{~B} / \mathrm{C}(4), 18 \mathrm{C}(1), 19 \mathrm{~A}(10), 19 \mathrm{~F}(72), 23 \mathrm{~F}(6), \mathrm{UT}(3)$ \\
\hline E-TE-DA-SXT & $184(24.1)$ & $\begin{array}{l}5(1), 6 \mathrm{~A}(4), 6 \mathrm{~B}(29), 9 \mathrm{~V}(1), 14(7), 15 \mathrm{~A}(5), 15 \mathrm{~B} / \mathrm{C}(10), 19 \mathrm{~A}(20), 19 \mathrm{~F} \\
(68), 23 \mathrm{~A}(2), 23 \mathrm{~F}(23), 34(3), 35 \mathrm{~B}(3), \mathrm{UT}(8)\end{array}$ \\
\hline E-TE-SXT-DA & $4(0.9)$ & $19 F(2), 23 \mathrm{~A}(1), 23 \mathrm{~F}(1)$ \\
\hline E-TE-SXT & $2(0.4)$ & $6 \mathrm{~B}(1), 19 \mathrm{~F}(1)$ \\
\hline E-DA-SXT & $17(4.1)$ & $6 \mathrm{~B}(4), 14(3), 19 \mathrm{~A}(1), 19 \mathrm{~F}(7), 23 \mathrm{~F}(1), 35 \mathrm{~B}(1)$ \\
\hline E-DA-SXT & $22(5.3)$ & $3(1), 6 \mathrm{~A}(2), 6 \mathrm{~B}(1), 14(5), 15 \mathrm{~A}(1), 19 \mathrm{~A}(2), 19 \mathrm{~F}(7), 23 \mathrm{~A}(3)$ \\
\hline Total number of isolates & $393(93.8)$ & \\
\hline
\end{tabular}

P: penicillin G; E: erythromycin; TE: tetracycline; DA: clindamycin; SXT: trimethoprim-sulfamethoxazole; CTX: cefotaxime; LEV: levofloxacin; LZD: linezolid; CL: chloramphenicol; UT: untypeable;

Table 3 Antibiotic resistance genes and virulence genes of $S$. pneumoniae isolated from children with CAP

\begin{tabular}{|c|c|c|c|c|c|c|c|c|}
\hline \multirow[t]{2}{*}{ Variables } & \multicolumn{2}{|c|}{ CC271 n (\%) $(n=182)$} & \multicolumn{2}{|c|}{ Non-CC271 n (\%) $(n=237)$} & \multicolumn{2}{|c|}{ Total $n(\%)(n=419)$} & \multirow[t]{2}{*}{$x^{2}$} & \multirow[t]{2}{*}{$P$} \\
\hline & Positive & Negative & Positive & Negative & Positive & Negative & & \\
\hline $\operatorname{erm}(\mathrm{B})$ & $168(92.3)$ & $14(7.7)$ & $217(91.6)$ & $20(8.4)$ & $385(91.9)$ & $34(8.1)$ & 0.08 & 0.781 \\
\hline $\operatorname{mef}(\mathrm{A} / \mathrm{E})$ & $156(85.7)$ & $26(14.3)$ & $83(35.0)$ & $154(65.0)$ & $239(57.0)$ & $180(43.0)$ & 107.96 & $<0.001$ \\
\hline tet $(\mathrm{M})$ & $178(97.8)$ & $4(2.2)$ & $224(94.9)$ & $13(5.1)$ & $402(95.9)$ & $17(4.1)$ & 1.61 & 0.205 \\
\hline tet $(\mathrm{K})$ & $0(0.0)$ & $182(100.0)$ & $3(1.3)$ & $234(98.7)$ & $3(0.7)$ & $416(99.3)$ & 0.26 & 0.180 \\
\hline tet $(\mathrm{L})$ & $0(0.0)$ & $182(100.0)$ & $7(3.0)$ & $230(97.0)$ & $7(1.7)$ & $412(98.3)$ & 5.46 & 0.021 \\
\hline tet $(\mathrm{O})$ & $3(1.6)$ & $179(98.4)$ & $7(3.0)$ & $230(97.0)$ & $10(2.4)$ & 409 (97.6) & 0.29 & 0.586 \\
\hline ply & $171(94.0)$ & $11(6.0)$ & $211(89.0)$ & $26(11.0)$ & $382(91.2)$ & $37(8.8)$ & 3.10 & 0.078 \\
\hline lytA & $182(100.0)$ & $0(0.0)$ & $221(93.2)$ & $16(6.8)$ & $403(96.2)$ & $16(3.8)$ & 12.77 & $<0.001$ \\
\hline psaA & $8(4.4)$ & $174(95.6)$ & $7(3.0)$ & $230(97.0)$ & $15(3.6)$ & 404 (96.4) & 0.62 & 0.431 \\
\hline$p s p A$ & $123(67.6)$ & $59(32.4)$ & $150(63.3)$ & 87 (36.7) & $273(65.2)$ & 146 (34.8) & 0.84 & 0.361 \\
\hline$r / r A$ & $91(50.0)$ & $91(50.0)$ & $48(20.3)$ & 189 (79.7) & $139(33.2)$ & $280(66.8)$ & 41.09 & $<0.001$ \\
\hline $\operatorname{sip} A$ & 154 (84.6) & $28(15.4)$ & $32(13.5)$ & $205(86.5)$ & $186(44.4)$ & $233(55.6)$ & 210.89 & $<0.001$ \\
\hline
\end{tabular}

Italic values indicate significance of $P$ value $(P<0.05)$

CAP: community-acquired pneumonia 

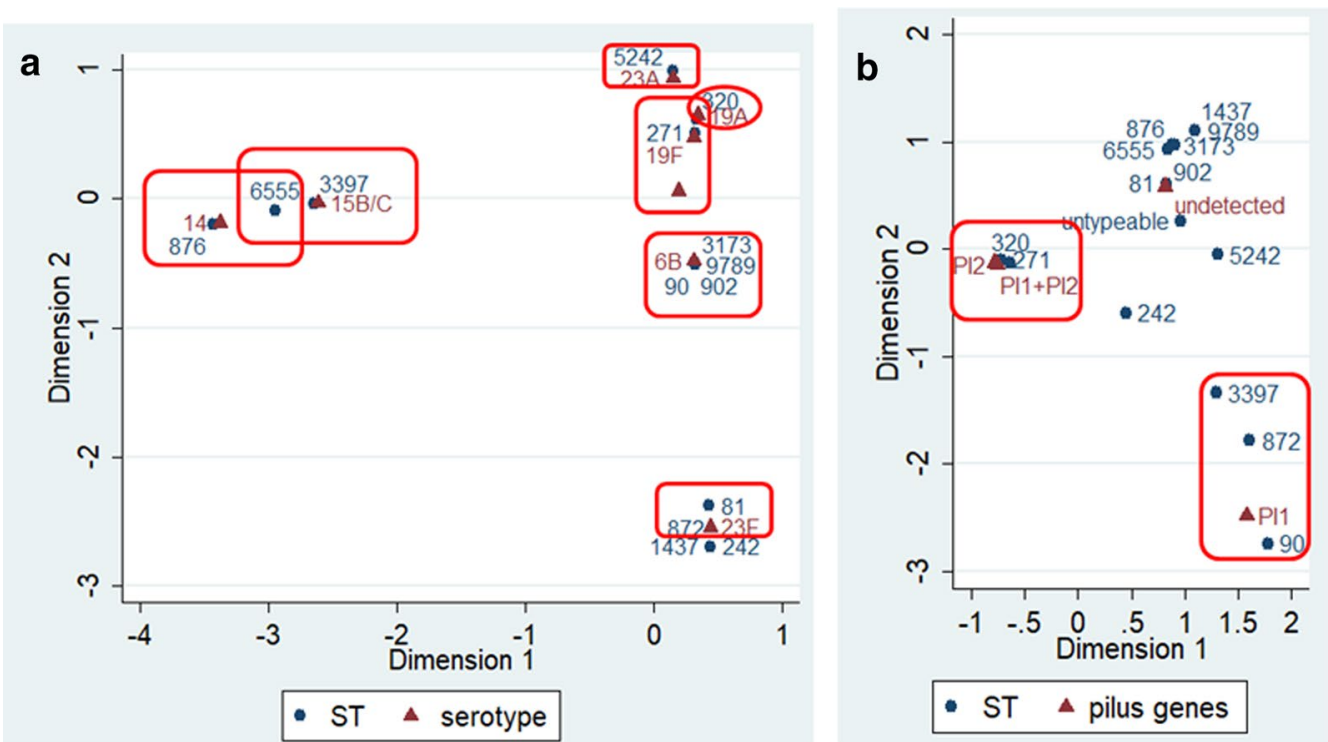

Fig. 2 Correspondence analysis for the relationship between serotypes and STs (a), and pilus genes and STs (b)

predominant serotypes were $19 \mathrm{~F}, 6 \mathrm{~B}, 23 \mathrm{~F}$, and $19 \mathrm{~A}$. The total coverage of PCV13 was $86.16 \%$. The positive carriage rates of $m e f(\mathrm{~A} / \mathrm{E}), \operatorname{ly} t A, r l r A$ and $\operatorname{sip} A$ were higher in CC271 isolates than that in non-CC271 isolates. The most interesting findings were that we found strong corresponding relationships between serotypes and STs, and between STs and PIs.

In this study, the predominant STs were ST271, ST320, and ST81, which were all MDR. The predominant CC was CC271, accounting for $41.4 \%$ of all the isolates. It was reported that the $\mathrm{CC} 271$ clone belonged to the known Taiwan $19 \mathrm{~F}^{14}$, which has been described as the major factor to spread MDR isolates internationally, including China [11, 18]. Our data showed that over $90 \%$ isolates, including the CC271 clone were MDR. Most of these isolates were resistant to erythromycin, tetracycline and trimethoprim-sulfamethoxazole, and over $90 \%$ isolates carried both erm(B) and tet(M) genes. Previous study revealed that $T n 6002$ was a result of the insertion of the erm(B) and $\operatorname{Tn} 916$ was a result of the insertion of the macrolide efflux genetic element mef(E), and both of which carried tet $(\mathrm{M})$ and were identical to the CC271 clone [19]. It was interesting that CC271 clone carried higher $m e f(\mathrm{~A} / \mathrm{E})$ rate than the non-CC271 clone, which was consistent with other studies[11, 20]. Reports from both Asian Network for Surveillance of Resistant Pathogens (ANSORP) and China revealed that the S. pneumoniae isolates had high resistance rate to the macrolides and tetracycline antibiotics [12, 21,22]. The combination of the above results suggest that both genetic background and antibiotic selective pressure had contributed to the spread of the CC271 clone.
It is believed that vaccination is not only a crucial way to reduce the burden of pneumococcal diseases in children, but also has a broad herd immunity effect in the whole population [23]. A vast number of epidemiological studies revealed that the incidence of pneumococcal diseases which were vaccine-covered serotypes decreased significantly after large-scale vaccination of PCV7 in the USA and Europe, especially the serotypes of 19F, 6B, 23F and $14[24,25]$. In this study, the potential coverage rates of PCV7 and PCV10 against CAP isolates were $73.0 \%$ and $73.5 \%$, respectively. This indicates that the PCV10 would not add much extra benefit than PCV7 if it is introduced into Western China, because the extra serotypes included in PCV10 (serotype 1, 5 and 7F) were rarely detected in our study. However, PCV13 would potentially provide $13 \%$ of additional coverage of identified serotypes among children aged $<5$ years and even $20 \%$ of additional coverage among children aged 1-2 years because serotype 19A was highly prevalent in this age group.

It was previously reported that the Taiwan $19 \mathrm{~F}^{-14}$ clone related to pneumococcal serotype 19A and 19F, which were spread extensively across China prior to the introduction of PCV7 and contributed to the prevalence of MDR S. pneumoniae isolates in China [26, 27].This positive association between the increase in serotypes 19A and 19F and the high epidemic of MDR CC271 isolates was also confirmed in other Asian countries such as Japan and South Korea before and after the introduction of PCV7 [28-31]. In developed countries such as the USA and Europe, the long-term effect of broad vaccination with PCV7 vaccine led to the increase of nonvaccine serotypes (serotype replacement), especially 
MDR-related serotype 19A [32]. Based on these findings, the vaccine immunization and protection effect could not entirely explain the emergence and dissemination of MDR-related serotypes of 19A and 19F, which related to the homogeneous genetic background of CC271 in Asian countries [31]. Evidence from multicenter surveillance in China demonstrated that $84.7 \%$ of the isolates of $19 \mathrm{~A}$ and $19 \mathrm{~F}$ belonged to $\mathrm{CC} 271$ [33], suggesting that in the area of where PCV7 vaccination rate of less than $10 \%$, the vaccine implication pressure could not entirely explain these phenomenon, and other risk factors (such as antibiotic use and younger age) may promote the dissemination of these isolates among children suffering from CAP [34]. Our data suggest that the PCV13 coverage rate was 87.3\% for all the MDR isolates, indicating that the PCV13 may have a potential benefit to reduce the spread of MDR isolates.

Recent evidence has revealed a potential association between pneumococcal serotypes and STs. Serotype 19F/ ST271 prevails in China, Czech Republic, Iceland, and South Africa [11, 35-37], serotype 19A/ST320 was prevalent in Asia and worldwide [32, 38], serotype 14/ST876 was prevalent in China [39], and serotype 23F/ST81was prevalent in Taiwan [40]. A good consistency between pneumococcal serotypes and STs was revealed in this study using the correspondence analysis. The consistency was also reported in previous studies, mostly in China $[11,32,34,39]$.

Pilus islet has capable of assisting S. pneumoniae collapsing mucosa, triggering mucosal inflammation and adherence to host tissue, which make S. pneumoniae more virulent. Previous study revealed that the pilus genes were associated with certain complex clonal of $S$. pneumoniae. For example, the $r l r A$ and $\operatorname{sip} A$ which encoded the PI-1 and PI-2 pilus islet have previously been described as positive among the Taiwan 19F-14 clone (CC271) [41]. Another study also found that the PCV7 non-vaccine serotype (19A) of S. pneumoniae also carried the pilus islet genes [42]. Consistent with above findings, our data demonstrated that $\mathrm{CC} 271$ has a great consistency with PI-1 and PI-2 pilus islets and carrying $m e f(\mathrm{~A} / \mathrm{E})$ gene. In addition, we found that certain pilus genes have corresponding relationships with certain STs, such as ST90/ST872/ST3397 and PI-1, ST320/271 and PI-1 + PI-2, and ST320/271 and PI-2. These findings indicate that pilus islets help the high virulence isolates such as CC271 spread among children suffered from CAP in Western China, and imply that the introduction of PCV13 would decrease the disease burden of CAP in this area.

This study has some limitations. First, this surveillance of CAP data was conducted only in two hospitals, which may limit the generalizability of our results. Results from this study need to be confirmed in future multiprovince or multinational surveillance studies. Second, some serotypes have not been identified, and further studies are needed to identify them in the future. However, the significant consistency between STs and serotypes and between STs and PIs of S. pneumoniae gives us a new insight into the spread of dominant complex clones among the children suffering from CAP. The time span of the sample collection was between January 2015 and January 2017; that is after the PCV7 was pulled off the Chinese market in 2015, but before PCV13 was introduced into Liuzhou, so this study can reflect the epidemiology of S. pneumoniae isolated from pediatric communityacquired pneumonia in pre-conjugate vaccine era in Western China.

In conclusion, this is the first study to focus on pediatric CAP-causing S. pneumoniae in Western China. Our findings indicate that S. pneumoniae CC271 isolates carry more resistance genes and virulence genes than non-CC271. Interestingly, there are strong corresponding relationships between serotypes and STs and between STs and PIs, which may provide new guidance for developing future pneumococcal vaccines. In addition, the high coverage rate of PCV13 suggests the necessity of introducing the PCV13 vaccine in Western China, which may reduce disease burden of CAP in this population.

\begin{abstract}
Abbreviations
S. Pneumoniae: Streptococcus pneumoniae; CAP: Community-acquired pneumonia; WHO: World Health Organization; PCVs: Pneumococcal conjugate vaccines; MDR: Multidrug-resistant; m-PCR: Multiplex polymerase chain reaction; MLST: Multilocus sequence typing; STs: Sequence types; CC: Clonal complex; ANSORP: Asian network for surveillance of resistant pathogens.
\end{abstract}

\section{Acknowledgements}

Not applicable.

\section{Authors' contributions}

JF and ZL designed the study and drafted an outline. LL, RY, SX, JC and XY participated in data analysis, JF draft of initial manuscript, $Z L, L L, R Y, S X, J C$ participated in diagnosed and collected the data, EM and XY revised the manuscript and all of authors approved the final content of this manuscript. All authors read and approved the final manuscript.

\section{Funding}

This work was funded by the Guangxi Medical and Health Project (Z20180022), the National Natural Science Foundation of China (No. 81973069), and the Liuzhou Science and Technology Bureau Project (2018BJ10504, 2018BJ10502). The funders had no role in study design, data collection and analysis, decision to publish, or preparation of the manuscript.

\section{Availability of data and materials}

We declare that the data supporting the conclusions of this article are available from the corresponding author on reasonable request.

\section{Ethics approval and consent to participate}

This study was approved by the Institutional Review Board of Liuzhou Maternity and Child Healthcare Hospital (No 2017003). A written informed consent was obtained from parents or legal guardians on behalf of the children involved in the study for collection of information and samples. The Ethics 
Committee also permitted the authors to use the patients records to write this article.

\section{Consent to publication}

Not applicable.

\section{Competing interests}

The authors declare that they have no competing interests.

\section{Author details \\ ${ }^{1}$ Department of Pediatric Intensive Care Unit, Department of Prevention and Health Care, Department of Pediatric, Department of Laboratory, Depart- ment of Neonatology, Liuzhou Maternity and Child Health Care Hospital, Liuzhou, China. ${ }^{2}$ Department of Social Medicine and Health Management, Xiangya School of Public Health, Central South University, Changsha, China. ${ }^{3}$ Laboratory of Molecular Epidemiology, School of Public Health, Guang- dong Pharmaceutical University, 283\# Jianghai Dadao, Haizhu District, 510310 Guangzhou, China. ${ }^{4}$ Children's Hospital of Michigan, Detroit, MI, USA. \\ ${ }^{5}$ Wayne State University School of Medicine, Detroit, MI, USA.}

Received: 18 May 2020 Accepted: 10 December 2020

Published online: 06 January 2021

\section{References}

1. World Health Organization. Fact Sheet - Pneumonia. 2016. "http://www. who.int/mediacentre/factsheets/fs331/en/. Accessed 22 August 2019

2. Rudan I, O'Brien KL, Nair H, Liu L, Theodoratou E, Qazi S, et al. Epidemiology and etiology of childhood pneumonia in 2010: estimates of incidence, severe morbidity, mortality, underlying risk factors and causative pathogens for 192 countries. J Glob Health. 2013;3:010401.

3. Principi N, Esposito S. Prevention of community-acquired pneumonia with available pneumococcal vaccines. Int J Mol Sci. 2016;18(1):30.

4. Elemraid MA, Rushton SP, Shirley MD, Thomas MF, Spencer DA, Eastham KM, Hampton F, Gorton R, Pollard K, Gennery AR, Clark JE. North East of England paediatric respiratory infection study group. Impact of the 7-valent pneumococcal conjugate vaccine on the incidence of childhood pneumonia. Epidemiol Infect. 2013;141(8):1697-704.

5. Simonsen L, Taylor RJ, Schuck-Paim C, Lustig R, Haber M, Klugman KP. Effect of 13-valent pneumococcal conjugate vaccine on admissions to hospital 2 years after its introduction in the USA: a time series analysis. Lancet Respir Med. 2014 May;2(5):387-94.

6. DeAntonio R, Yarzabal JP, Cruz JP, Schmidt JE, Kleijnen J. Epidemiology of community-acquired pneumonia and implications for vaccination of children living in developing and newly industrialized countries: A systematic literature review. Hum Vaccin Immunother. 2016 Sep;12(9):2422-40.

7. Ning G, Wang $X$, Wu D, Yin Z, Li Y, Wang H, Yang W. The etiology of community-acquired pneumonia among children under 5 years of age in mainland China, 2001-2015: A systematic review. Hum Vaccin Immunother. 2017 Nov;13(11)(2):2742-50.

8. Liu Y, Wang H, Chen M, Sun Z, Zhao R, Zhang L, et al. Serotype distribution and antimicrobial resistance patterns of Streptococcus pneumoniae isolated from children in China younger than 5 years. Diagn Microbiol Infect Dis. 2008;61(3):256-63.

9. Pan F, Han L, Huang W, Tang J, Xiao S, Wang C, et al. Serotype distribution, antimicrobial susceptibility, and molecular epidemiology of streptococcus pneumoniae isolated from children in Shanghai, China. PLoS One. 2015;16(11):e0142892.

10. Lim WS, Levy ML, Macfarlane JT, British Thoracic Society Community Acquired Pneumonia Guidelines Committee. Community acquired pneumonia. Management in primary care. BMJ. 2010 Aug;19:341:c4469.

11. Fu J, Li L, Liang Z, Xu S, Lin N, Qin P, Ye X, McGrath E. Etiology of acute otitis media and phenotypic-molecular characterization of Streptococcus pneumoniae isolated from children in Liuzhou, China. BMC Infect Dis. 2019:19(1):168

12. Li L, Fu J, Li S, Guo D, Chen Z, Chen S, Ye X. Phenotypic and molecular characterization of Streptococcus pneumoniae in pre-conjugate vaccine era: a Chinese hospital-based retrospective study. Vaccine. 2018:36(5):599-605
13. Ahn JG, Choi SY, Kim DS, Kim KH. Enhanced detection and serotyping of Streptococcus pneumoniae using multiplex polymerase chain reaction. Korean J Pediatr. 2012;55(11):424-9.

14. Geng Q, Zhang T, Ding Y, Tao Y, Lin Y, Wang Y, et al. Molecular characterization and antimicrobial susceptibility of Streptococcus pneumoniae isolated from children hospitalized with respiratory infections in Suzhou. China PLoS One. 2014;9(4):e93752.

15. Malhotra-Kumar S, Lammens C, Piessens J, Goossens H. Multiplex PCR for simultaneous detection of macrolide and tetracycline resistance determinants in streptococci. Antimicrob Agents Chemother. 2005;49(11):4798-800.

16. Shakrin NN, Masri SN, Taib NM, Nordin SA, Jamal F, Desa MN. Genotypic characterization of Malaysian human isolates of Streptococcus pneumoniae from carriage and clinical sources. Comp Immunol Microbiol Infect Dis. 2014;37(5-6):347-54.

17. Enright MC, Spratt BG. A multilocus sequence typing scheme for Streptococcus pneumoniae: identification of clones associated with serious invasive disease. Microbiology. 1998;144(Pt 11):3049-60.

18. Zhou L, Ma X, Gao W, Yao KH, Shen AD, Yu SJ, Yang YH. Molecular characteristics of erythromycin-resistant Streptococcus pneumoniae from pediatric patients younger than five years in Beijing, 2010. BMC Microbiol. 2012:12:228

19. Del Grosso M, Northwood JG, Farrell DJ, Pantosti A. The macrolide resistance genes erm(B) and mef(E) are carried by Tn2010 in dual-gene Streptococcus pneumoniae isolates belonging to clonal complex CC271. Antimicrob Agents Chemother. 2007;51(11):4184-6.

20. Bowers JR, Driebe EM, Nibecker JL, Wojack BR, Sarovich DS, Wong AH, Brzoska PM, Hubert N, Knadler A, Watson LM, Wagner DM, Furtado MR, Saubolle M, Engelthaler DM, Keim PS. Dominance of multidrug resistant CC271 clones in macrolide-resistant streptococcus pneumoniae in Arizona. BMC Microbiol. 2012 Jan;18:12:12

21. Li QH, Yao KH, Yu SJ, Ma X, He MM, Shi W, Yang YH. Spread of multidrugresistant clonal complex 271 of serotype 19F Streptococcus pneumoniae in Beijing, China: characterization of serotype 19F. Epidemiol Infect. 2013;141(12):2492-6.

22. Kim SH, Song JH, Chung DR, Thamlikitkul V, Yang Y, Wang H, Lu M, So TM, Hsueh PR, Yasin RM, Carlos CC, Pham HV, Lalitha MK, Shimono N, Perera J, Shibl AM, Baek JY, Kang CI, Ko KS, Peck KR, ANSORP Study Group. Changing trends in antimicrobial resistance and serotypes of Streptococcus pneumoniae isolates in Asian countries: an Asian Network for Surveillance of Resistant Pathogens (ANSORP) study. Antimicrob Agents Chemother. 2012 Mar;56(3):1418-26.

23. Oishi K, Tamura K, Akeda Y. Global control of pneumococcal infections by pneumococcal vaccines. Trop Med Health. 2014 Jun;42(2 Suppl):83-6.

24. Chibuk TK, Robinson JL, Hartfield DS. Pediatric complicated pneumonia and pneumococcal serotype replacement: trends in hospitalized children pre and post introduction of routine vaccination with Pneumococcal Conjugate Vaccine (PCV7). Eur J Pediatr. 2010 Sep;169(9):1123-8.

25. Balsells E, Guillot L, Nair H, Kyaw MH. Serotype distribution of Streptococcus pneumoniae causing invasive disease in children in the post-PCV era: a systematic review and meta-analysis. PLoS One. 2017;12(5):e0177113.

26. Yang F, Xu XG, Yang MJ, Zhang YY, Klugman KP, McGee L. Antimicrobial susceptibility and molecular epidemiology of Streptococcus pneumoniae isolated from Shanghai. China Int J Antimicrob Agents. 2008;32(5):386-91.

27. Ma X, Yao KH, Xie GL, Zheng YJ, Wang CQ, Shang YX, Wang HY, Wan LY, Liu L, Li CC, Ji W, Xu XW, Wang YT, Xu PR, Yu SJ, Yang YH. Characterization of erythromycin-resistant Streptococcus pneumoniae isolates causing invasive diseases in Chinese children. Chin Med J. 2013;126(8):1522-7.

28. Oodate M, Kimura K, Banno H, Yokoyama S, Jin W, Wachino Jl, Hasegawa Y, Arakawa Y. Predominance of Serogroup 19 CC320/271 among Penicillin-Nonsusceptible Streptococcus pneumoniae Isolates after Introduction of the PCV7 Vaccine in Several Regions of Japan. Jpn J Infect Dis. 2018;71(1):14-20.

29. Imai S, Ito Y, Ishida T, Hirai T, Ito I, Maekawa K, Takakura S, linuma Y, Ichiyama S, Mishima M, Kansai Community Acquired Pneumococcal Pneumonia Study Group. High prevalence of multidrug-resistant Pneumococcal molecular epidemiology network clones among Streptococcus 
pneumoniae isolates from adult patients with community-acquired pneumonia in Japan. Clin Microbiol Infect. 2009 Nov;15(11):1039-45.

30. Eun BW, Kim SJ, Cho EY, Lee J, Choi EH, Lee HJ. Genetic structure of Streptococcus pneumoniae isolated from children in a tertiary care university hospital, in Korea, 1995 to 2005. Diagn Microbiol Infect Dis. 2010 Dec;68(4):345-51.

31. Shin J, Baek JY, Kim SH, Song JH, Ko KS. Predominance of ST320 among Streptococcus pneumoniae serotype 19A isolates from 10 Asian countries. J Antimicrob Chemother. 2011 May;66(5):1001.

32. Isturiz R, Sings HL, Hilton B, Arguedas A, Reinert RR, Jodar L. Streptococcus pneumoniae serotype 19A: worldwide epidemiology. Expert Rev Vaccines. 2017 Oct;16(10):1007-27.

33. Zhao C, Zhang F, Chu Y, Liu Y, Cao B, Chen M, Yu Y, Liao K, Zhang L, Sun Z, Hu B, Lei J, Hu Z, Zhang X, Wang H. Phenotypic and genotypic characteristic of invasive pneumococcal isolates from both children and adult patients from a multicenter surveillance in China 2005-2011. PLoS One. 2013;8(12):e82361.

34. Yu YY, Xie XH, Ren L, Deng Y, Gao Y, Zhang Y, Li H, Luo J, Luo ZX, Liu EM. Epidemiological characteristics of nasopharyngeal Streptococcus pneumoniae strains among children with pneumonia in Chongqing, China. Sci Rep. 2019;9(1):3324.

35. Žemličková H, Mališová L, Španělová P, Jakubů V, Kozáková J, Musílek M, Medvecký M, Papagiannitsis CC. Molecular characterization of serogroup 19 Streptococcus pneumoniae in the Czech Republic in the post-vaccine era. J Med Microbiol. 2018 Aug;67(8):1202.

36. Hjálmarsdóttir M, Kristinsson KG. Epidemiology of penicillin-non-susceptible pneumococci in Iceland, 1995-2010. J Antimicrob Chemother. 2014 Apr;69(4):940-6.
37. Ndlangisa KM, du Plessis M, Wolter N, de Gouveia L, Klugman KP, von Gottberg A. GERMS-SA. Population snapshot of Streptococcus pneumoniae causing invasive disease in South Africa prior to introduction of pneumococcal conjugate vaccines. PLoS One. 2014 Sep 18;9(9):e107666.

38. Shin J, Baek JY, Kim SH, Song JH, Ko KS. Predominance of ST320 among Streptococcus pneumoniae serotype 19A isolates from 10 Asian countries. J Antimicrob Chemother. 2011 May;66(5):1001-4.

39. Shi W, Li J, Dong F, Qian S, Liu G, Xu B, Zhou L, Xu W, Meng Q, Wang Q, Shen K, Ma L, Yao K. Serotype distribution, antibiotic resistance pattern, and multilocus sequence types of invasive Streptococcus pneumoniae isolates in two tertiary pediatric hospitals in Beijing prior to PCV13 availability. Expert Rev Vaccines. 2019 Jan;18(1):89-94.

40. Hsieh YC, Huang YC, Lin HC, Ho YH, Chang KY, Huang LM, Hsueh PR. Characterization of invasive isolates of Streptococcus pneumoniae among Taiwanese children. Clin Microbiol Infect. 2009 Nov; 15(11):991-6.

41. Zähner D, Gudlavalleti A, Stephens DS. Increase in pilus islet 2-encoded pili among Streptococcus pneumoniae isolates, Atlanta, Georgia, USA. Emerg Infect Dis. 2010;16(6):955-62.

42. Wierzbowski AK, Karlowsky JA, Adam HJ, Nichol KA, Hoban DJ. Zhanel GG. Canadian antimicrobial resistance Alliance. Evolution and molecular characterization of macrolide-resistant Streptococcus pneumoniae in Canada between 1998 and 2008. J Antimicrob Chemother. 2014;69(1):59-66.

\section{Publisher's Note}

Springer Nature remains neutral with regard to jurisdictional claims in published maps and institutional affiliations.
Ready to submit your research? Choose BMC and benefit from:

- fast, convenient online submission

- thorough peer review by experienced researchers in your field

- rapid publication on acceptance

- support for research data, including large and complex data types

- gold Open Access which fosters wider collaboration and increased citations

- maximum visibility for your research: over $100 \mathrm{M}$ website views per year

At BMC, research is always in progress.

Learn more biomedcentral.com/submissions 